\title{
Identification and evaluation of the novel genes for transcript normalization during female gametophyte development in
} sugarcane

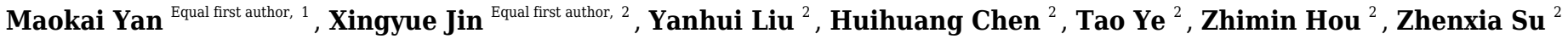

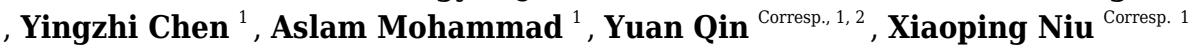 \\ ${ }^{1}$ Guangxi Key Laboratory of Sugarcane Biology, State Key Laboratory for Conservation and Utilization of Subtropical Agro-Bioresources, College of \\ Agriculture, Guangxi University, Nanning, China \\ ${ }^{2}$ Key Lab of Genetics, Breeding and Multiple Utilization of Crops, Ministry of Education, Fujian Provincial Key Laboratory of Haixia Applied Plant Systems \\ Biology, College of Life Science,, Fuzhou, China \\ Corresponding Authors: Yuan Qin, Xiaoping Niu \\ Email address: yuanqin@fafu.edu.cn, 407127145@qq.com
}

Background. Sugarcane (Saccharum spontaneum L.), the major sugar and biofuel feedstock crop, is cultivated mainly by vegetative propagation worldwide due to the infertility of female reproductive organs resulting in the reduction of quality and output of sugar. Deciphering the gene expression profile during ovule development will improve our understanding of the complications underlying sexual reproduction in sugarcane. Optimal reference genes are essential for elucidating the expression pattern of a given gene by quantitative real-time PCR (qRT-PCR).

Method. In this study, based on transcriptome data obtained from sugarcane ovule, eighteen candidate reference genes were identified, cloned, and their expression levels were evaluated across five developmental stages ovule (AC, MMC, Meiosis, Mitosis, and Mature).

Results. Our results indicated that $F A B 2$ and MOR1 were the most stably expressed genes during sugarcane female gametophyte development. Moreover, two genes, cell cycle-related genes REC8 and $C D K$, were selected, and their feasibility was validated. This study provides important insights into the female gametophyte development of sugarcane and reports novel reference genes for gene expression research on sugarcane sexual reproduction.

Keywords: Sugarcane; novel genes; Transcriptome analysis; Female gametophyte. 


\section{Identification and evaluation of the novel genes for 2 transcript normalization during female gametophyte 3 development in sugarcane}

4 Maokai Yan ${ }^{1 \#}$, Xingyue Jin²\#, Yanhui Liu ${ }^{2}$, Huihuang Chen ${ }^{2}$, Tao $\mathrm{Ye}^{2}$, Zhimin $\mathrm{Hou}^{2}$, Zhenxia

$5 \mathrm{Su}^{2}$, Yingzhi Chen ${ }^{1}$, Mohammad Aslam ${ }^{1}$, Yuan Qin ${ }^{1,2^{*}}$, Xiaoping Niu ${ }^{*}$

6

7

8

${ }^{1}$ Guangxi Key Laboratory of Sugarcane Biology, State Key Laboratory for Conservation and Utilization of Subtropical Agro-Bioresources, College of Agriculture, Guangxi University, Nanning, 530004, China; 562640038@qq.com (M.Y.); 847588526@qq.com (Y.C.); aslampmb1@gmail.com (M.A.); xpniu0613@126.com (X.N.)

${ }^{2}$ Key Lab of Genetics, Breeding and Multiple Utilization of Crops, Ministry of Education, Fujian Provincial Key Laboratory of Haixia Applied Plant Systems Biology, College of Life Science, Fujian Agriculture and Forestry University, Fuzhou 350002, China; 2075025151@qq.com (X.J.); 591276899@qq.com (Y.L.); 1198017900@qq.com (H.C.); 1154583981@qq.com (T.Y.); 543923365@qq.com (Z.H.); 30871820@qq.com (Z.S.)

\# These authors contributed to this article equally.

*Corresponding authors. E-mail: yuanqin@fafu.edu.cn; xpniu0613@126.com.

\section{ABSTRACT}

Background. Sugarcane (Saccharum spontaneum L.), the major sugar and biofuel feedstock crop, is cultivated mainly by vegetative propagation worldwide due to the infertility of female reproductive organs resulting in the reduction of quality and output of sugar. Deciphering the gene expression profile during ovule development will improve our understanding of the complications underlying sexual reproduction in sugarcane. Optimal reference genes are essential for elucidating the expression pattern of a given gene by quantitative real-time PCR (qRT-PCR).

Method. In this study, based on transcriptome data obtained from sugarcane ovule, eighteen candidate reference genes were identified, cloned, and their expression levels were evaluated across five developmental stages ovule (AC, MMC, Meiosis, Mitosis, and Mature).

Results. Our results indicated that $F A B 2$ and $M O R 1$ were the most stably expressed genes during sugarcane female gametophyte development. Moreover, two genes, cell cycle-related genes $R E C 8$ and $C D K$, were selected, and their feasibility was validated. This study provides important 
36 insights into the female gametophyte development of sugarcane and reports novel reference 37 genes for gene expression research on sugarcane sexual reproduction.

Keywords: Sugarcane; novel genes; Transcriptome analysis; Female gametophyte.

\section{INTRODUCTION}

Sugarcane (Saccharum spontaneum L.) is an erect perennial plant that belongs to the Poaceae family, responsible for $80 \%$ of the world's sugar production and accounting for the fifth most valuable crop worldwide (Zhang et al. 2018). With high fiber content and alcohol production, sugarcane also has excellent potential in the paper industry, alternative biofuel, and animal feed. Annually, sugarcane is cultivated in more than 90 countries, with harvested yield at 1.83 billion metric tons, and generating a revenue close to $\$ 57$ billion per year. Therefore, many researchers are putting tremendous efforts into sugarcane germplasm innovation and improvement (Yang et al. 2020). Very little progress has been obtained through normal sexual propagation and/or hybridization due to the degeneration of sugarcane reproductive organs (Wang et al. 2008). Thus, unveiling the fundamental mechanism of the sugarcane reproductive developmental process by genetics, genomics, and molecular technology is becoming indispensable to develop improved varieties (Hoang et al. 2017). The normal development of female and male gametophyte is essential for reproduction, directly influencing crop breeding and agronomic traits (Kawamoto et al. 2020). Previous studies revealed that the sugarcane seed setting rate is low by sexual hybridization, and the reason behind this was that the female gametophyte of sugarcane is sterile (Wang et al. 2020). Therefore, understanding the underlying reasons for female gametophyte development in sugarcane is a vital endeavor. The Saccharum spontaneum L. genome (http://www.life.illinois.edu/ming/downloads/ Spontaneum_genome/) and RNA-seq data could help us elucidate the complicated molecular mechanisms of the genetics and signal transduction networksduring female gametophyte development (Zhang et al. 2018). Furthermore, gene expression analysis of female gametophyte development could foster an understanding of the mechanisms underlying sugarcane reproductive development (Wang et al. 2020). Because of its authenticity, sensitivity and efficiency, quantitative real-time PCR (qRT-PCR) is one of the most common methods used to measure the abundance of a given gene (Bustin and Dorudi 2002; Guenin et al. 2009). Nonetheless, the authenticity and reliability of qRT-PCR results could be easily affected by the variations such as mRNA concentration, reverse transcription efficiency, 
67 enzyme activity, among other factors (Huggett et al. 2005). To reduce the impacts of variations 68 and acquire accurate results, appropriate references should be adopted as an internal control to

69 70 71 72 73 74 75 76 77 78

normalize the results of the target gene. For an ideal reference gene, its transcript abundance should remain constant across all tested tissues, regardless of experimental treatments and developmental stages (Huggett et al. 2005). Numerous studies demonstrate that the transcription level of most reported reference genes highly depend on the experimental conditions of the tissue samples, and no such reference gene can be universally used in a wide range of tissue samples (Guenin et al. 2009). As a result, no reference genes can be widely applied in different experiments. Until the systematic evaluation of reference genes is completed, it cannot be used to normalize qRT-PCR in specific species and/or conditions (Jarosova and Kundu 2010). Previously, several systematic research studies have been done on several commercial crops, including rice (Narsai et al. 2010), wheat (Long et al. 2010), etc.Those studies identified suitable housekeeping genes that play essential cellular roles, including $18 \mathrm{SrRNA}, U B Q 5$ and $E F 1 \alpha$, to normalize the variation, paving ways for follow-up transcriptional studies. Over the past few years, an increasing number of studies have shown that the traditional housekeeping gene could not work as stable normalization factors. Meanwhile, the selection of reference genes at the transcriptome level has found many novel genes which can be expressed stably, such as with apple (Storch et al. 2015), pineapple sexual organs (Jin et al. 2020), pear peel (Chen et al. 2020), and papaya (Zhu et al. 2012). Jin et al. revealed novel identified genes CCR and RPS4 behave better than the traditional housekeeping genes in pineapple ovule and stamen normalization (Jin et al. 2020). Chen et al. identified a novel gene named NAPl (Nucleosome Assembly Protein 1) that performed better in pear peel (Chen et al. 2020). Taken together, genome-wide identification work could provide new candidate reference genes and avoid the inappropriate selection of internal reference genes. However, no genome-wide or transcriptome-based reference gene selection has been conducted in Saccharum spontaneum L, limiting further studies on the expression normalization of many key genes (Zhang et al. 2018). Based on RNA-seq data, the hundreds of novel reference genes and 8 traditional housekeeping genes were identified to obtain the steady expressed reference genes for normalization during sugarcane female gametophyte development. As a result of this analysis, FAB2 and MOR1, which were never identified as reference genes before, were selected as optimal genes during female gametophyte development in sugarcane. Those two selected genes were further validated by normalizing the transcript 
98 abundance of two known marker genes (CDK and REC8) across all the experimental samples.

99 To our knowledge, this study comprehensively evaluated the reference genes during the five 100 developmental stages female gametophyte in sugarcane for the first time. This study will provide 101 information for further normalization of key genes affecting sugarcane female gametophyte 102 development.

103 Materials \& Methods

104 Plant material

105 The sugarcane (Saccharum spontaneum L.) cultivar Yuetang 91-976 provided by State Key 106 Laboratory for Conservation and Utilization of Subtropical Agro-Bioresources (Guangxi, China) 107 was used for the experiment. When the plants reached the florescence stage, five different stages 108 of the sugarcane female gametophyte (i.e., Archesporial cell (AC), Megaspore mother cell 109 (MMC), Meiosis, Mitosis and Mature) were collected (Figure S3). The samples were harvested 110 in three biological replicates and quickly frozen with liquid nitrogen before storing at $-80^{\circ} \mathrm{C}$.

\section{RNA extraction and RNA-seq}

112 Total RNA was isolated by the Omega Total RNA kit II (R6934-02, USA). The evaluation of 113 RNA quality was performed by gel electrophoresis and 2000 spectrophotometer assessment at $114260 \mathrm{~nm}$ (NanoDrop, Thermo Fisher Scientific), and Illumina sequencing was referred to by the 115 method of Zhao et al. (2018). Each sample had three independent biological replicates, and one $116 \mu \mathrm{g}$ of total RNA was used for library preparation. After sequencing, the adapter sequences and 117 low-quality reads were filtered, and the clean reads were aligned to the sugarcane reference 118 genome by STAR v2.5.0 software. The SourceForge Subread package feature Count v1.5.0 was 119 used for the alignment results for gene quantification.

120 The cDNA was synthesized using the ThermoScript RT-PCR kit (Life Technologies) in a 20 $121 \mu \mathrm{L}$ volume reaction under the program: $42^{\circ} \mathrm{C}$ for $15 \mathrm{~min}$ and $85^{\circ} \mathrm{C}$ for $15 \mathrm{~s}$. The qRT-PCR was 122 performed according to the SYBR Premix RT reagent kit system (TaKaRa, Dalian, China).

\section{Candidate gene selection and primer design}

124 Based on the average RPKM values, the CV (i.e. coefficient of variation) values were 125 calculated for each gene under the corresponding experimental stage. This resulted in 50 126 candidates with the low CV values (Supplemental Table 1). We considered only the 18 127 candidates with the highest RPKM values to avoid identifying genes with absent as latent 128 references. The name, ID and sequence information of these genes were obtained from the datas 
129 uploaded

by

Ming

Laboratory

130 (https://www.life.illinois.edu/ming/downloads/Spontaneum_genome/). This led to identification

131 of 12 novel selected reference genes (ATPase, FAB2, LOG2, MCB1, MOR1, TIV110, VHA,

$132 V L N 3, A R M$, Expressed, GET4, PP2A, and TIC110) and 6 traditional genes (EF1 $\alpha, T U B 6, A C T 7$,

133 ACTIN, GAPDH, and $U B C 28$ ) (Table 1).

\section{4 qRT-PCR and statistical analysis}

135 We used Bio-Rad Real-time PCR (Foster, USA) for qRT-PCR with SYBR Premix Ex Taq 136 plus (TaKaRa, China) in $20 \mu \mathrm{L}$ volume reaction. The qRT-PCR cycle program applied in this 137 experiment was as follows: $96^{\circ} \mathrm{C}$ for $2 \mathrm{~min}, 40$ cycles at $95^{\circ} \mathrm{C}$ for $5 \mathrm{~s}, 60^{\circ} \mathrm{C}$ for $34 \mathrm{~s}, 95^{\circ} \mathrm{C}$ for 15

138 s. Two technical replicates and three independent biological replicates were performed for each

139 reaction, and the negative control reactions without template were performed in parallel.

140 According to the standard curve and formula, the correlation coefficient (R2) and amplification

141 efficiency $(\mathrm{E})$ were computed: $\mathrm{E}=[10-(1 /$ slope $)-1] \times 100 \%$.

142 In order to identify whether the expression of each candidate gene was stable, three statistical 143 software packages, geNorm (Vandesompele et al. 2002), NormFinder (Andersen et al. 2004), 144 and BestKeeper (Pfaffl 2001), were adopted. For geNorm and NormFinder algorithms, the

145 relative expression values of all candidate genes were calculated from the raw Ct values using 146 the formula: E_ $\Delta \mathrm{Ct}$, where $\Delta \mathrm{Ct}=$ each corresponding $\mathrm{Ct}$ value - the minimum $\mathrm{Ct}$ value. Then, 147 the resulting values were imported into NormFinder and geNorm to determine the gene 148 expression stability. For BestKeeper analysis, the coefficient variation (CV) and standard 149 deviation (SD) were computed using the raw $\mathrm{Ct}$ values. Finally, the comprehensive rankings of 150 the optimal reference genes were acquired by calculating the geometric mean.

151

152

\section{Results}

\section{Candidate genes selection}

154 Transcriptome analysis across five different developmental stages of sugarcane ovule at AC, 155 MMC, Meiosis, Mitosis and Mature (Figure S3) resulted in 50 candidate reference genes with 156 the high average read per kilobase per million mapped reads (RPKM) values. SD values across all stages were calculated and then the ratio of SD and Mean Value (i.e. coefficient of variation, $\mathrm{CV}$ ) were calculated as a reference index. Since lower CV values indicate less deviation, genes with $\mathrm{CV}$ values less than 0.6 were picked out from 50 candidate genes. A total of eighteen genes, 
160 including twelve novel genes (ATPase, FAB2, LOG2, MCB1, MOR1, TIV110, VHA, VLN3, 161 ARM, Expressed, GET4, PP2A, and TIC110) and 6 traditional genes (EF1 $\alpha, T U B 6, A C T 7$, $162 A C T I N, G A P D H$, and $U B C 28$ ) were screened out (Table 1). The CV values of twelve novel 163 genes ranged from 0.06 to 0.09 , which were much lower than eight traditional reference genes $164(0.25-0.56)$ (Figure 1A). We further calculated the relative expression level of all candidates 165 across all five experimental stages to obtain more accurate data. Except for EF1 $\alpha$ and TUB6, the

166

167

168

169

170

171

172

173

174

175

176

177

178

179

180

181

182

183

184

185

186

187

188

189

novel genes showed very stable expression. In contrast, all the traditional housekeeping gene expression levels varied considerably, suggesting that the expression of novel genes may be more stable than conventional housekeeping genes during sugarcane ovule development (Figure 1). Taken together, the results of RNA-seq showed that most of the new genes are better than traditional housekeeping genes in sugarcane ovule normalization studies.

\section{PCR specificity and amplification efficiency of candidate reference genes}

To investigate the transcriptional behaviors of candidate reference genes, RT-PCR and qRTPCR experiments were adopted to confirm the primer specificity of all candidate genes. In RTPCR results, the nonspecific amplification band and primer dimer were not observed and no signal was detected in the negative controls of all tested primers (Figure S1). In the qRT-PCR experiment, all genes had a relatively single melting curve, indicating that the primers used in the experiment had high specificity (Figure S2). Besides, the standard curve was established with a series of 10-fold diluted cDNA samples and then the correlation coefficient $\left(\mathrm{R}^{2}\right)$ and amplification efficiency (E) of each gene was calculated. The results showed that $E$ values of all genes varied from 0.97 (ATPase) to 1.04 (VLN3 and TUB6), and the $\mathrm{R}^{2}$ of all standard curves ranged from 0.995 (TUB6 and GET4) to 0.999 (GET4, ARM, TIC110 and EF1 $\alpha$ ), showing their high correlation with their average value (Table 1).

\section{Expression profiles of candidate reference genes}

The top eighteen genes were selected as candidate reference genes for qRT-PCR, and the $\mathrm{Ct}$ values were examined across all ovule developmental sugarcane samples to detect the transcript abundance and expression stability. The lower the $\mathrm{Ct}$ value means the higher the expression level, and vice versa. As showed in Figure 2, the $\mathrm{Ct}$ values of the 10 novel genes ranged between 4.55 and 30.71, while the commonly used housekeeping genes, Actin and ACT7, with the broadest range $6.37 \sim 31.09$ (Actin) and $28.36 \sim 7.05$ (ACT7), showed the worst expression 
190 stability. These results were also consistent with their CV values, 0.54 (Actin) and 0.50 (ACT7),

191 the two highest CV values of all candidates (Table 1). In contrast, the three novel genes FAB2, 192 with the $\mathrm{Ct}$ values varied from 26.15 to 30.71 , followed by VLN3 (4.97 23.23) and MOR1

193 (7.68 22.71), which showed minimal variation. Therefore, these genes are speculated as more 194 suitable for normalizing sugarcane ovule development.

\section{Stability evaluation by geNorm, BestKeeper and NormFinder analysis}

196 To obtain an accurate result, three standard programs BestKeeper, geNorm and NormFinder 197 were combined to detect the expression stability of eighteen candidate reference genes. For the 198 geNorm algorithm, the average variation of tested genes is defined as M-values, with lower M 199 value and more stability. As shown in Table 2, MCB1 and LOG2 showed the most stable 200 expression level owing to their lowest $M$ values (0.15). While the M value of TUB6 was the 201 highest, indicating that TUB6 is the most variable among these candidates. The NormFinder 202 algorithm is based on a mathematical model that can identify the most suitable reference gene by 203 calculating both the overall variation of all candidates and variation between the given samples 204 (Andersen et al. 2004). The results demonstrated that MOR1, with the stability value of 0.09, 205 followed by FAB2 (0.10), TIC110 (0.10), were the most stable genes. $M C B 1$, which ranked in 206 the first position by geNorm, was ranked in the fourth position by NormFinder. Not surprisingly, 207 TUB6 was also evaluated as the most unreliable gene by NormFinder (Table 2). BestKeeper is 208 also an EXCEL-based tool determining the most stable reference gene by calculating SD and 209 CV. Both SD value and CV value were negatively correlated with gene expression stability, and 210 thus candidate genes with lower SD value and lower CV value exhibit higher normalization 211 reliability (Pfaffl 2001). As shown in Table 2, FAB2 with the lowest value (CV (\%) $\pm \mathrm{SD}=5.48$ $212 \pm 1.52)$ was considered as the most reliable normalization factor, followed by VLN3 $(6.28 \pm$ $2131.63)$, TIV110 (11.29 \pm 2.68$)$, while TUB6 (20.38 \pm 4.32$)$ followed by EF1 $\alpha(21.69 \pm 5.35)$ were 214 identified as the most unstable normalization factors.

\section{Consensus Ranking of Candidate Reference Genes}

216 Owing to different statistical approaches among the three algorithms, the best candidate genes 217 generated by each algorithm were not for their same ranking. To obtain a comprehensive 218 ranking, the geometric mean method was introduced to create consensus results described by Niu 
219 et al. (2015). As shown in Table 2, FAB2, MOR1 and MCB1 were considered as the three best 220 genes by comprehensive analysis for sugarcane female gametophyte development.

221 Moreover, the pairwise variation (V) values were also calculated by geNorm to confirm the 222 minimum number of reference genes required for accurate normalization. According to 223 Vandesompele's research, when the $\mathrm{V}$ values between two adjacent normalization factors $(\mathrm{Vn} / \mathrm{V}$ $224 \mathrm{n}+1$ ) were higher than the recommended value 0.15 , one more reference gene than $\mathrm{n}$ is required 225 (Vandesompele et al. 2002). As shown in Figure 3, the first pairwise variation value is lower 226 than the suggested value 0.15. Therefore, two top-ranked genes are enough for the reliable 227 normalization. The third gene adopted will make no significant difference for accurate 228 normalization across these sugarcane female gametophyte developmental stages. The results of 229 consensus ranking showed $F A B 2$ and $M O R 1$ are the best choices for normalizing transcription 230 during female gametophyte development in sugarcane.

231

232

233

234

235

236

237

238

239

240

241

242

243

244

245

246

247

248

\section{Reference Gene Validation}

To validate the effectiveness of reference genes selected in this study, the expression of two transcripts, $C D K$ and $R E C 8$, were analyzed by qRT-PCR analysis across the different ovule stages in sugarcane. $C D K$ encodes a cyclin-dependent protein kinase, playing key roles in the progression of the cell proliferation or cell cycle in eukaryotes (Endo et al. 2012). REC8 is reported to encode a meiotic cohesion protein that could bind sister chromatids and anchor chromosomes to the axis, thus is critical for chromosome segregation during meiosis and eukaryotes gametophyte production (Hsieh et al. 2020). As depicted in Figure 4, when stable genes $F A B 2$ and/or MOR1 used as the normalization factors, the expression level of $R E C 8$ gene increased from $\mathrm{AC}$ stage and peaked at the MMC stage, and was reduced at the meiosis stage, followed by an increase at mitosis stage. The trend of relative expression of REC 8 and $C D K$ was consistent with RNA-seq data. On the contrary, when the unstable reference genes ATPase and/or TUB6 were selected for validation, the expression profiles of $C D K$ and $R E C 8$ showed significant fluctuations, about 3-fold high than that of most genes at MMC stage, and the trend of expression profiles was also changed after the meiosis stage (Figure. 4).

\section{Discussion}

Due to the sterility of sugarcane female gametophyte, it is cultivated mainly by vegetative propagation in agriculture production (Wang et al. 2008; Hoang et al. 2017; Kawamoto et al. 
249 2020) leading to its variety heterogeneity being reduced greatly and easily affected by abiotic 250 and biotic factors (Kumar et al. 2016). To overcome said problems, efforts should be made to 251 understand the development of the sugarcane female gametophyte. The RNA-seq and expression 252 profiles analysis are efficient approaches to understand genes involved in the specific organ 253 development process (Hoang et al. 2017). Real-time quantitative PCR (qRT-PCR) is one of the 254 most common methods used to measure the gene expression abundance with accuracy, 255 sensitivity, and efficiency (Bustin and Dorudi 2002; Guenin et al. 2009). However, the 256 accurateness and strength of qRT-PCR results rely on the stably expressed normalization genes 257 (Guenin et al. 2009; Huggett et al. 2005; Jarosova and Kundu 2010).

258 Although there have been many studies on the screening of reliable reference genes under 259 different conditions, most of those studies focused on the traditional reference gene selections 260 due to the deficiency of sugarcane genome and transcriptome data (Iskandar et al. 2004; Ling et 261 al. 2014; Guo et al. 2014; de Andrade et al. 2017). For example, eEF-1a was used as the optimal 262 candidate in hormone treatment experiments (Ling et al. 2014). GADPH was identified as the 263 most suitable gene under salinity and drought conditions (Guo et al. 2014; de Andrade et al. 264 2017). Nonetheless, the expression of these known housekeeping genes is not stable during 265 sugarcane ovule development (Figure 1 and 2). RNA-seq data was introduced to select stably 266 expressed genes under heavy metal stress and cold stress in sugarcane to broaden the candidate 267 range of reference genes. APRT (Anthranilate phosphoribosyl transferase) was selected as the 268 best reference gene for miRNA expression analysis under Sorghum Mosaic Virus infection and 269 cold stress in sugarcane, respectively (Ling et al. 2019; Yang et al. 2016). In our study, reference 270 genes were genome-widely identified based on transcriptome data across the sugarcane ovule 271 developmental stages. A total of eighteen reference genes, including twelve novel genes 272 (ATPase, FAB2, LOG2, MCB1, MOR1, TIV110, VHA, VLN3, ARM, Expressed, GET4, PP2A, 273 and TIC110) and six traditional genes (EF1 $\alpha, T U B 6, A C T 7, A C T I N, G A P D H$, and UBC28), were 274 identified as candidates. After stability evaluation, two novel genes FAB2 and MOR1 were 275 selected as the most optimal normalization factors during sugarcane female gametophyte 276 development.

$277 \quad F A B 2$ encodes a FATTY ACID SYNTHESIS protein named stearoyl-ACP desaturase and 278 plays an essential role in fatty acid desaturation. In Arabidopsis thaliana, AtFAB2 is highly 279 expressed in embryo and endosperm and participates in oil storage in mature seed (Jin et al. 
280

281

282

283

284

285

286

287

288

289

290

291

292

293

294

295

296

297

298

299

300

301

302

303

304

305

306

307

308

2017). In Oryza sativa, OsFAB2-9, OsFAB2-1 and OsFAD3-1 were constitutively expressed in reproductive organs and showed relatively higher abundance (E et al. 2019). For Nicotiana benthamiana, three $N b S A C P D$ genes shared high similarity to AtFAB2, predominantly expressed in ovules, and played essential roles in maintaining membrane composition in ovule for female fertility (Zhang et al. 2014). These results implied this gene and its homolog were functionally conservative during the progress of reproductive organs formation. Therefore, FAB2, as a stable reference gene identified in this study may also play a vital role in sugarcane female gametophyte development.

The MORl gene belongs to the ARM repeat superfamily containing CLIP-associated (CLASP) $\mathrm{N}$ terminal and plays an essential role in maintaining microtubule stability (Grallert et al. 2006). The homologous gene in yeast, XMAP215 encodes microtubule polymerase, is associated with microtubule formation underlying chromosome segregation spatiotemporally (Yukawa et al. 2019). In animals including Drosophila, The XMAP215 gene was also identified as the regulator of microtubule arrangement, equipping protein with unique spatial configuration and further playing numerous vital functions (Brittle and Ohkura 2005). Similarly, in angiosperms, such as Arabidopsis thaliana, Selaginella moellendorffii, Volvox carteri, Oryza sativa, and Physcomitrella patens, MORI regulates the cell division and expansion via controlling microtubule arrays of the cell cytoskeleton. In our study, the MORI gene was identified as part of stably expressed genes in sugarcane female gametophyte development, implying that the MOR1 gene may be involved in microtubule formation followed by chromosome segregation during ovule development in sugarcane.

\section{Conclusions}

In summary, this study is the first genome-wide reference gene identification for normalization of qRT-PCR analysis during sugarcane female gametophyte development. Based on genome and transcriptome data, all putative candidates were selected and screened by their $\mathrm{CV}$ values, and then the expression stabilities of eighteen putative candidates, including six traditional housekeeping genes and twelve novel genes were further evaluated by three popular algorithms. Finally, two stably expressed genes FAB2 and MOR1 were determined as the optimum reference genes for sugarcane female gametophyte development. Taken together, our 
309

310

311

312

313

314

315

316

317

318

319

320

321

322

323

324

325

326

327

328

329

330

331

332

333

334

335

336

337

338

339

340

341

342

343

344

345

346

347

study not only enriches the reference genes selected for the relative species but also provides the directions for studying the mechanism of the sugarcane ovule development.

Supplementary Materials: The following are available onlines, Figure S1: Amplified products of 18 candidate reference genes were separated by $1.5 \%$ agarose gel electrophoresis. Figure S2: the Melt Peak of 18 candidate reference genes, CDK and REC8 in the process of qRT-PCR. Figure S3: The morphology of the five different stages of the development of sugarcane female gametophytes. Table S1: The top 50 stably expressed genes for different developmental stages of sugarcane female gametophyte, Table S2. The qRT-PCR data ( $\mathrm{Ct}$ vaules) for 18 candidate reference genes in different developmental stages of sugarcane female gametophyte, Table S3: The qRT-PCR data and RPKM values for CDK and REC8 in different developmental stages of sugarcane female gametophyte.

\section{Funding}

This work was supported by Science and Technology Major Project of Guangxi (Gui Ke 2018266-Z01), National Natural Science Foundation of China (31800262; U1605212; 31761130074; 31600249; 31700279), China Postdoctoral Science Foundation (2018M632564), Weng Hongwu Academic Innovation Research Fund of Peking University, and a Guangxi Distinguished Experts Fellowship.

\section{Acknowledgements}

We wish to thank all members of the Qin lab for their suggestions and discussion of the results.

\section{References}

Andersen CL, Jensen JL, Orntoft TF (2004) Normalization of real-time quantitative reverse transcriptionPCR data: a model-based variance estimation approach to identify genes suited for normalization, applied to bladder and colon cancer data sets. Cancer Res 64 (15):5245-5250. doi:10.1158/00085472.CAN-04-0496

Brittle AL, Ohkura H (2005) Mini spindles, the XMAP215 homologue, suppresses pausing of interphase microtubules in Drosophila. Embo J 24 (7):1387-1396. doi:10.1038/sj.emboj.7600629

Bustin SA, Dorudi S (2002) The value of microarray techniques for quantitative gene profiling in molecular diagnostics. Trends Mol Med 8 (6):269-272. doi:Pii S1471-4914(02)02334-1

Chen CM, Wang TY, Cai ZM, Xie GF, Chen ZY, Yuan YF, Wang W, Xie Q, Guan XY, Chen QX, Chen JQ (2020) Genome-wide identification and validation of optimal reference genes for gene expression normalization in pear peel. Plant Growth Regul 92 (2):249-261. doi:10.1007/s10725020-00634-z

de Andrade LM, Brito MD, Peixoto RF, Marchiori PER, Nobile PM, Martins APB, Ribeiro RV, Creste S (2017) Reference genes for normalization of qPCR assays in sugarcane plants under water deficit. Plant Methods 13. doi:ARTN 2810.1186/s13007-017-0178-2

E ZG, Chen C, Yang JY, Tong HH, Li TT, Wang L, Chen HQ (2019) Genome-wide analysis of fatty acid desaturase genes in rice (Oryza sativa L.). Sci Rep-Uk 9. doi:ARTN 19445 
348

349

350

351

352

353

354

355

356

357

358

359

360

361

362

363

364

365

366

367

368

369

370

371

372

373

374

375

376

377

378

379

380

381

382

383

384

385

386

387

388

389

390

391

392

393

394

395

396

10.1038/s41598-019-55648-z

Endo M, Nakayama S, Umeda-Hara C, Ohtsuki N, Saika H, Umeda M, Toki S (2012) CDKB2 is involved in mitosis and DNA damage response in rice. Plant J 69 (6):967-977. doi:10.1111/j.1365-313X.2011.04847.x

Grallert A, Beuter C, Craven RA, Bagley S, Wilks D, Fleig U, Hagan IM (2006) S-pombe CLASP needs dynein, not EB1 or CLIP170, to induce microtubule instability and slows polymerization rates at cell tips in a dynein-dependent manner. Gene Dev 20 (17):2421-2436. doi:10.1101/gad.381306

Guenin S, Mauriat M, Pelloux J, Van Wuytswinkel O, Bellini C, Gutierrez L (2009) Normalization of qRT-PCR data: the necessity of adopting a systematic, experimental conditions-specific, validation of references. J Exp Bot 60 (2):487-493. doi:10.1093/jxb/ern305

Guo JL, Ling H, Wu QB, Xu LP, Que YX (2014) The choice of reference genes for assessing gene expression in sugarcane under salinity and drought stresses. Sci Rep-Uk 4. doi:ARTN 7042

10.1038/srep07042

Hoang NV, Furtado A, Mason PJ, Marquardt A, Kasirajan L, Thirugnanasambandam PP, Botha FC, Henry RJ (2017) A survey of the complex transcriptome from the highly polyploid sugarcane genome using full-length isoform sequencing and de novo assembly from short read sequencing. Bmc Genomics 18. doi:ARTN 395

10.1186/s12864-017-3757-8

Hsieh YYP, Makrantoni V, Robertson D, Marston AL, Murray AW (2020) Evolutionary repair: Changes in multiple functional modules allow meiotic cohesin to support mitosis. Plos Biol 18 (3). doi:ARTN e3000635

10.1371/journal.pbio.3000635

Huggett J, Dheda K, Bustin S, Zumla A (2005) Real-time RT-PCR normalisation; strategies and considerations. Genes Immun 6 (4):279-284. doi:10.1038/sj.gene.6364190

Iskandar HM, Simpson RS, Casu RE, Bonnett GD, Maclean DJ, Manners JM (2004) Comparison of reference genes for quantitative real-time polymerase chain reaction analysis of gene expression. Plant Mol Biol Rep 22 (4):325-337. doi:Doi 10.1007/Bf02772676

Jarosova J, Kundu JK (2010) Validation of reference genes as internal control for studying viral infections in cereals by quantitative real-time RT-PCR. Bmc Plant Biology 10. doi:Artn 146

10.1186/1471-2229-10-146

Jin CY, Li D, Gao CH, Liu KG, Qi SH, Duan SW, Li ZX, Gong JY, Wang JJ, Hai JB, Chen MX (2017) Conserved Function of ACYL-ACYL CARRIER PROTEIN DESATURASE 5 on Seed Oil and Oleic Acid Biosynthesis between Arabidopsis thaliana and Brassica napus. Frontiers in Plant Science 8. doi:ARTN 1319

10.3389/fpls.2017.01319

Jin XY, Hou ZM, Zhao LH, Liu LP, Priyadarshani SVGN, Wang LL, Huang YM, Chen FQ, Qin Y (2020) Genome-Wide Identification and Evaluation of New Reference Genes in Pineapple (Ananas comosus L.) during Stamen and Ovule Development. Trop Plant Biol 13 (4):371-381. doi:10.1007/s12042-020-09269-w

Kawamoto N, Del Carpio DP, Hofmann A, Mizuta Y, Kurihara D, Higashiyama T, Uchida N, Torii KU, Colombo L, Groth G, Simon R (2020) A Peptide Pair Coordinates Regular Ovule Initiation Patterns with Seed Number and Fruit Size. Curr Biol 30 (22):4352-+. doi:10.1016/j.cub.2020.08.050

Kumar D, Arora A, Poonia AK, Kajla S (2016) Effect of various types of sugars and gelling agents on in vitro multiplication and different potting mixtures on survival rate of in vitro raised plants of commercial cultivars of sugarcane (Co-7717). Annals of Agri Bio Research 21 (1):1-4

Ling H, Huang N, Xu LP, Peng Q, Liu F, Yang YT, Que YX (2019) Suitable Reference Genes/miRNAs for qRT-PCR Normalization of Expression Analysis in Sugarcane Under Sorghum mosaic virus Infection. Sugar Tech 21 (5):780-793. doi:10.1007/s12355-019-00712-1

Peer] reviewing PDF | (2021:03:59477:2:0:NEW 3 Sep 2021) 
397

398

399

400

401

402

403

404

405

406

407

408

409

410

411

412

413

414

415

416

417

418

419

420

421

422

423

424

425

426

427

428

429

430

431

432

433

434

435

436

437

438

439

440

441

442

443

444

445

446

447

Ling H, Wu QB, Guo JL, Xu LP, Que YX (2014) Comprehensive Selection of Reference Genes for Gene Expression Normalization in Sugarcane by Real Time Quantitative RT-PCR. Plos One 9 (5). doi:ARTN e97469

10.1371/journal.pone.0097469

Long XY, Wang JR, Ouellet T, Rocheleau H, Wei YM, Pu ZE, Jiang QT, Lan XJ, Zheng YL (2010) Genome-wide identification and evaluation of novel internal control genes for Q-PCR based transcript normalization in wheat. Plant Mol Biol 74 (3):307-311. doi:10.1007/s11103-010-96668

Narsai R, Ivanova A, Ng S, Whelan J (2010) Defining reference genes in Oryza sativa using organ, development, biotic and abiotic transcriptome datasets. Bmc Plant Biology 10. doi:Artn 56

10.1186/1471-2229-10-56

Niu X, Qi J, Zhang G, Xu J, Tao A, Fang P, Su J (2015) Selection of reliable reference genes for quantitative real-time PCR gene expression analysis in Jute (Corchorus capsularis) under stress treatments. Front Plant Sci 6:848. doi:10.3389/fpls.2015.00848

Pfaffl MW (2001) A new mathematical model for relative quantification in real-time RT-PCR. Nucleic Acids Res 29 (9):e45. doi:10.1093/nar/29.9.e45

Storch TT, Pegoraro C, Finatto T, Quecini V, Rombaldi CV, Girardi CL (2015) Identification of a Novel Reference Gene for Apple Transcriptional Profiling under Postharvest Conditions. Plos One 10 (3). doi:ARTN e0120599

10.1371/journal.pone.0120599

Vandesompele J, De Preter K, Pattyn F, Poppe B, Van Roy N, De Paepe A, Speleman F (2002) Accurate normalization of real-time quantitative RT-PCR data by geometric averaging of multiple internal control genes. Genome Biol 3 (7):RESEARCH0034. doi:10.1186/gb-2002-3-7-research0034

Wang LL, Li Y, Jin XY, Liu LP, Dai XZ, Liu YH, Zhao LH, Zheng P, Wang XM, Liu YQ, Lin DS, Qin $Y$ (2020) Floral transcriptomes reveal gene networks in pineapple floral growth and fruit development. Commun Biol 3 (1). doi:ARTN 500

10.1038/s42003-020-01235-2

Wang LP, Jackson PA, Lu X, Fan YH, Foreman JW, Chen XK, Deng HH, Fu C, Ma L, Aitken KS (2008) Evaluation of sugarcane $\mathrm{x}$ Saccharum spontaneum progeny for biomass composition and yield components. Crop Sci 48 (3):951-961. doi:10.2135/cropsci2007.10.0555

Yang X, Luo Z, Todd J, Sood S, Wang J (2020) Genome-wide association study of multiple yield traits in a diversity panel of polyploid sugarcane (Saccharum spp.). Plant Genome 13 (1):e20006. doi: $10.1002 / \operatorname{tpg} 2.20006$

Yang YT, Zhang X, Chen Y, Guo JL, Ling H, Gao SW, Su YC, Que YX, Xu LP (2016) Selection of Reference Genes for Normalization of MicroRNA Expression by RT-qPCR in Sugarcane Buds under Cold Stress. Frontiers in Plant Science 7. doi:ARTN 86

10.3389/fpls.2016.00086

Yukawa M, Kawakami T, Pinder C, Toda T (2019) Two XMAP215/TOG Microtubule Polymerases, Alp14 and Dis1, Play Non-Exchangeable, Distinct Roles in Microtubule Organisation in Fission Yeast. International Journal of Molecular Sciences 20 (20). doi:ARTN 5108

$10.3390 / \mathrm{ijms} 20205108$

Zhang J, Zhang X, Tang H, Zhang Q, Hua X, Ma X, Zhu F, Jones T, Zhu X, Bowers J, Wai CM, Zheng C, Shi Y, Chen S, Xu X, Yue J, Nelson DR, Huang L, Li Z, Xu H, Zhou D, Wang Y, Hu W, Lin J, Deng Y, Pandey N, Mancini M, Zerpa D, Nguyen JK, Wang L, Yu L, Xin Y, Ge L, Arro J, Han JO, Chakrabarty S, Pushko M, Zhang W, Ma Y, Ma P, Lv M, Chen F, Zheng G, Xu J, Yang Z, Deng F, Chen X, Liao Z, Zhang X, Lin Z, Lin H, Yan H, Kuang Z, Zhong W, Liang P, Wang G, Yuan Y, Shi J, Hou J, Lin J, Jin J, Cao P, Shen Q, Jiang Q, Zhou P, Ma Y, Zhang X, Xu R, Liu J, Zhou Y, Jia H, Ma Q, Qi R, Zhang Z, Fang J, Fang H, Song J, Wang M, Dong G, Wang G, Chen Z, Ma T, Liu H, Dhungana SR, Huss SE, Yang X, Sharma A, Trujillo JH, Martinez MC, Hudson M, Riascos JJ, Schuler M, Chen LQ, Braun DM, Li L, Yu Q, Wang J, Wang K, Schatz MC, Heckerman D, Van Sluys MA, Souza GM, Moore PH, Sankoff D, VanBuren R, Paterson AH,

Peer] reviewing PDF | (2021:03:59477:2:0:NEW 3 Sep 2021) 
Nagai C, Ming R (2018) Allele-defined genome of the autopolyploid sugarcane Saccharum spontaneum L. Nat Genet 50 (11):1565-1573. doi:10.1038/s41588-018-0237-2 desaturase, NbSACPD-C, is critical for ovule development in Nicotiana benthamiana. Plant J 80 (3):489-502. doi:10.1111/tpj.12649

Zhu X, Li X, Chen W, Chen J, Lu W, Chen L, Fu D (2012) Evaluation of new reference genes in papaya for accurate transcript normalization under different experimental conditions. Plos One 7

456 (8):e44405. doi:10.1371/journal.pone.0044405 


\section{Figure 1}

Identification and evaluation of optimal reference genes based on RNA-seq data in sugarcane ovule at different developmental stages.

(A) Statistical analysis of CV and RPKM values of 18 potential candidate genes identified based on RPKM values from the RNA-seq data. The data point in scatter plot shows the variation of given gene's expression across all tested stages, the horizontal line represents $\mathrm{CV}=0.2$. Each box represents RPKM values of given gene in box and whiskers plot. (B) Relative expression level of 18 candidate genes was given by dividing RPKM values by average expression values across all sugarcane ovule developmental stages. 
A

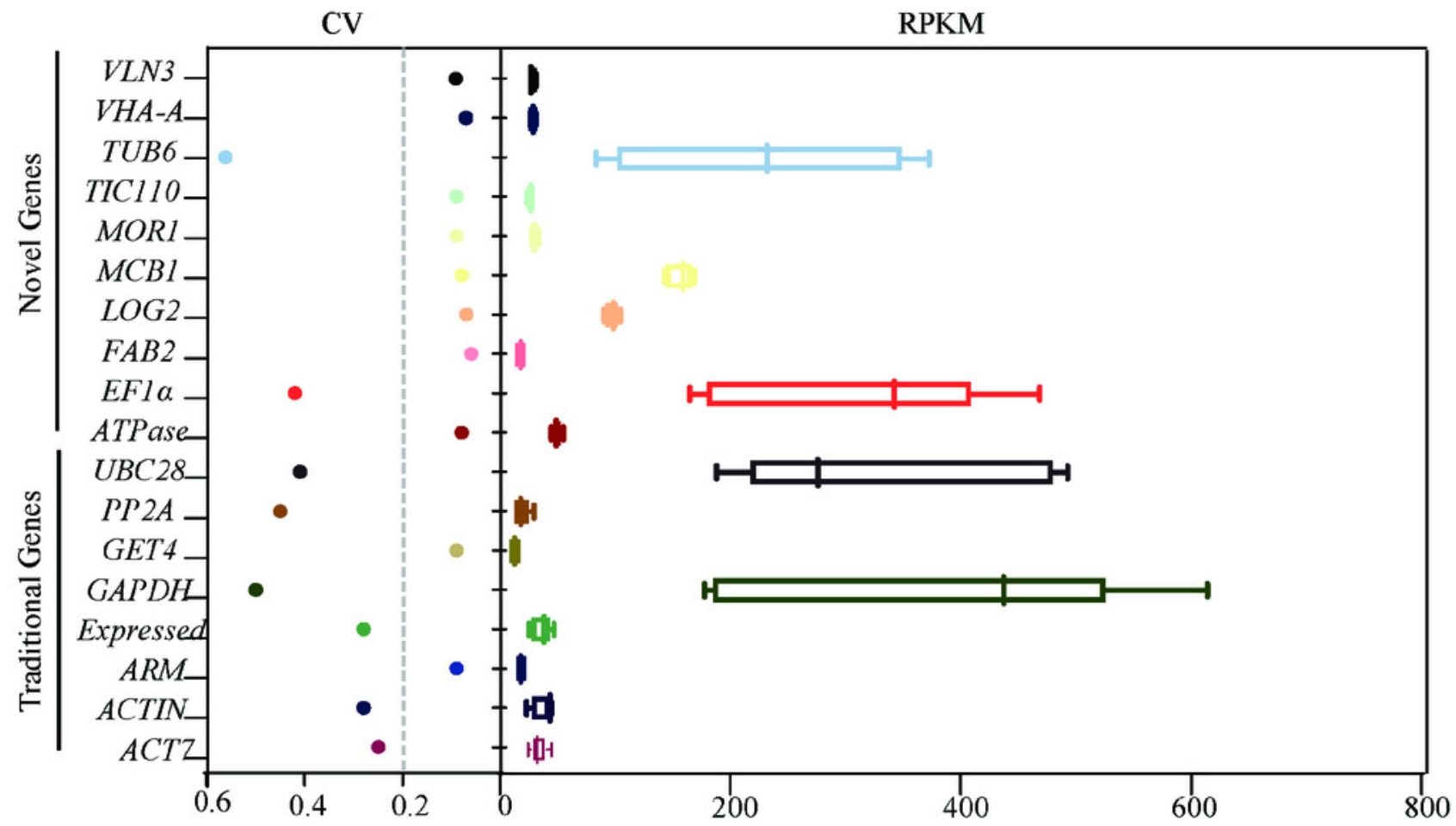

B

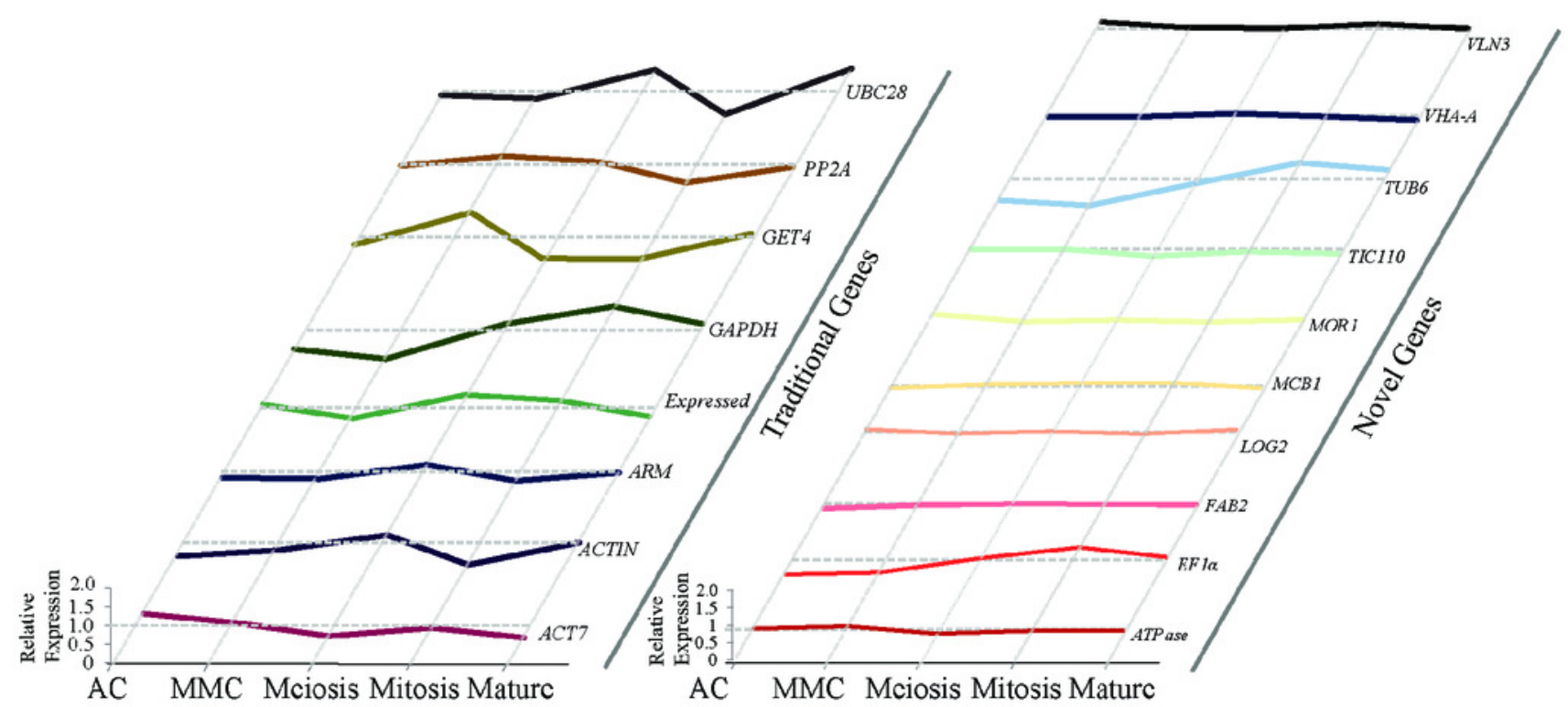


Figure 2

Ct values of all 18 candidate genes in sugarcane ovule developmental samples

The raw data of Ct values of 18 genes derived from all stages of sugarcane ovule developmental stages were collected and described using the box and whiskers plot. The box is determined from $25^{\text {th }}$ to $75^{\text {th }}$ percentiles, and the line across the box represents the median. The whiskers represent percentiles from $10^{\text {th }}$ to $90^{\text {th }}$.

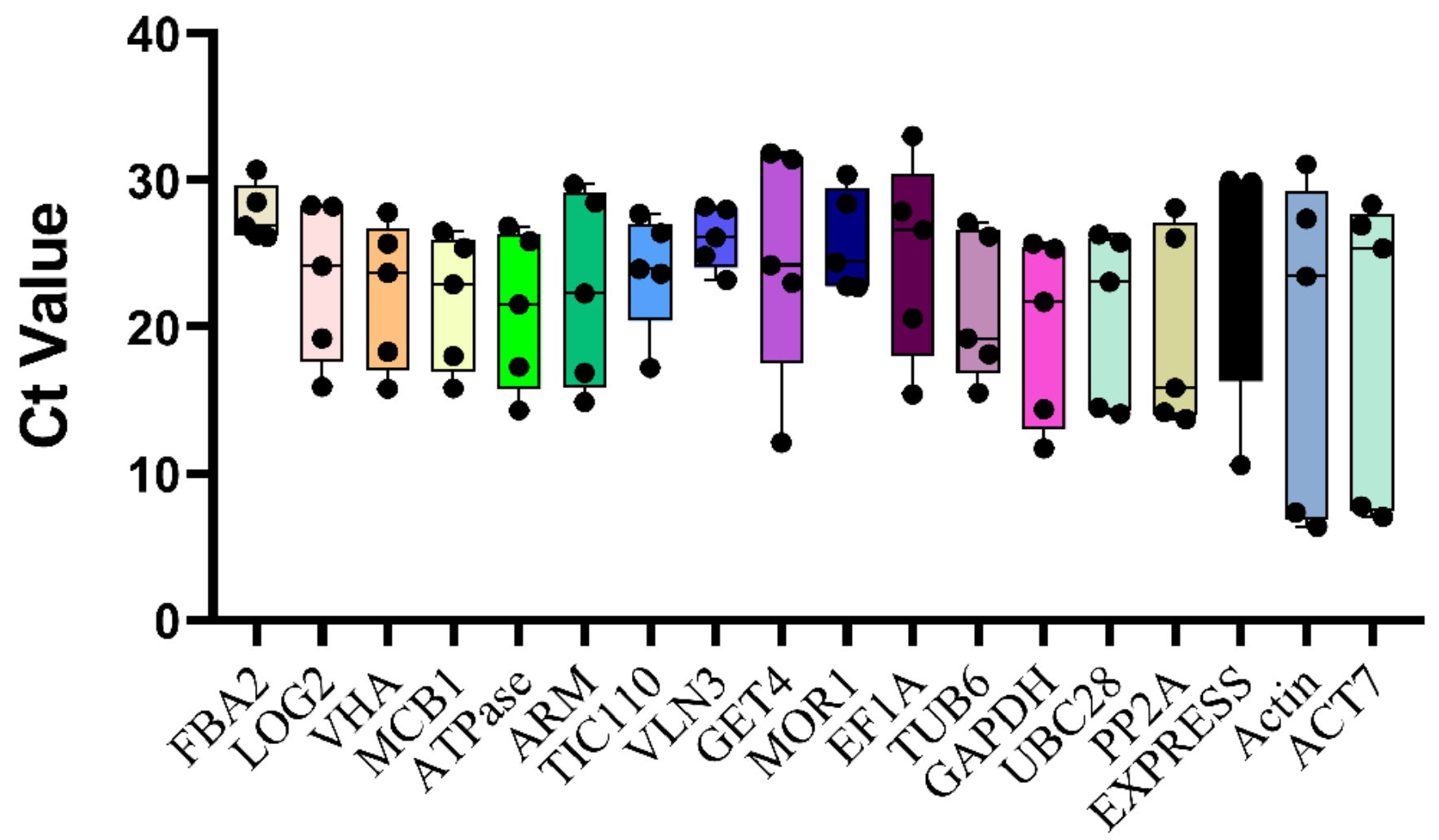


Figure 3

Comprehensive evaluation and selection of 10 novel genes

Pairwise variation $(\mathrm{Vn} / \mathrm{Vn}+1)$ given by geNorm. Pairwise variation values were calculated to determine the optimal number of reference genes.

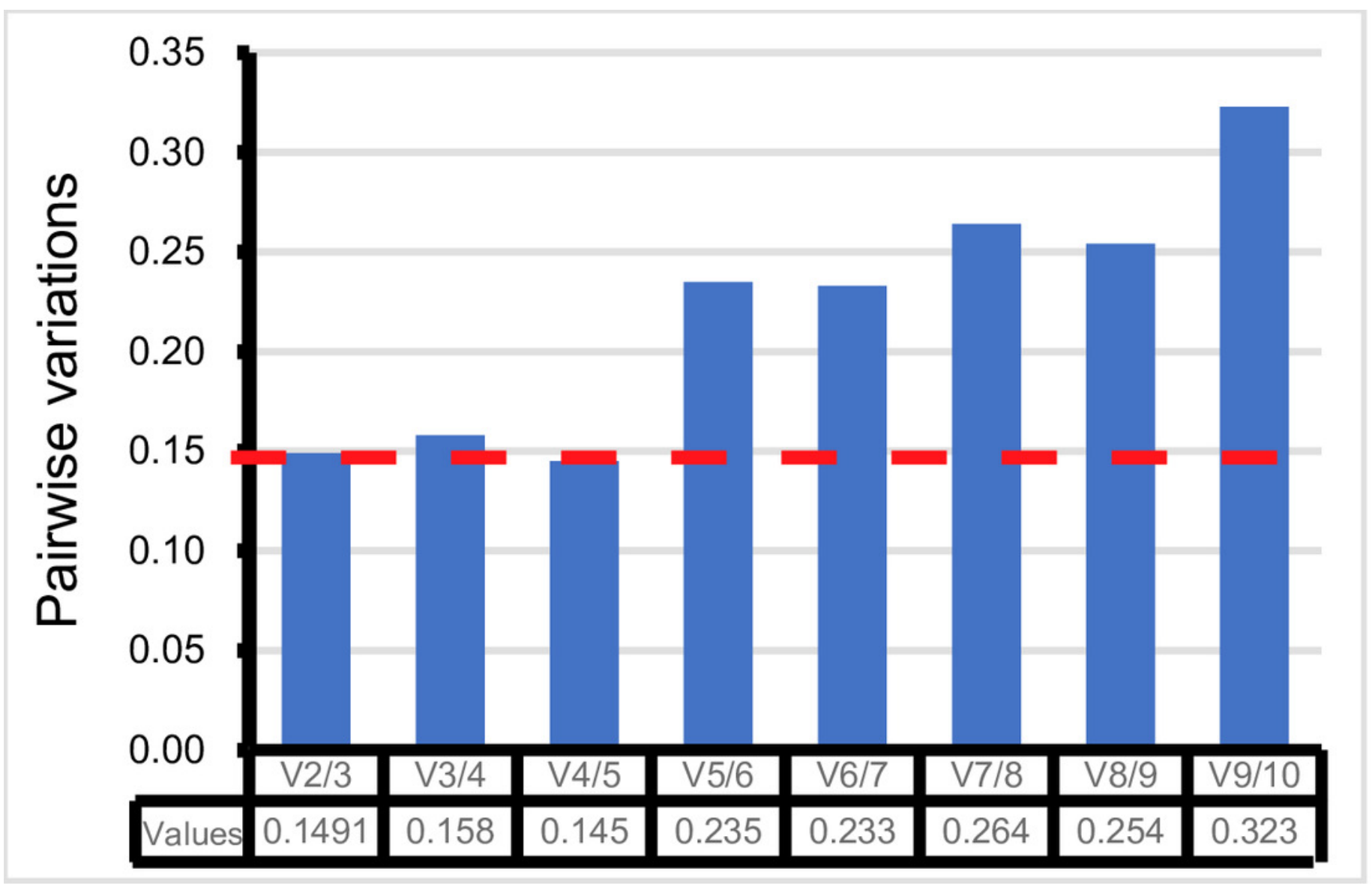




\section{Figure 4}

Relative quantification of target genes in sugarcane ovule samples using two most stable genes and two least genes

The relative expression levels of CDK (A) and REC8 (B) normalized by the most/least stable reference genes across different sugarcane ovule development stage by qRT-PCR and RPKM values. Bars indicate the standard error $( \pm \mathrm{SE})$ determined from three biological replicates. $* * *$ indicates significant differences $(p<0.01)$, and * represents differences $(p<0.05)$. 
A

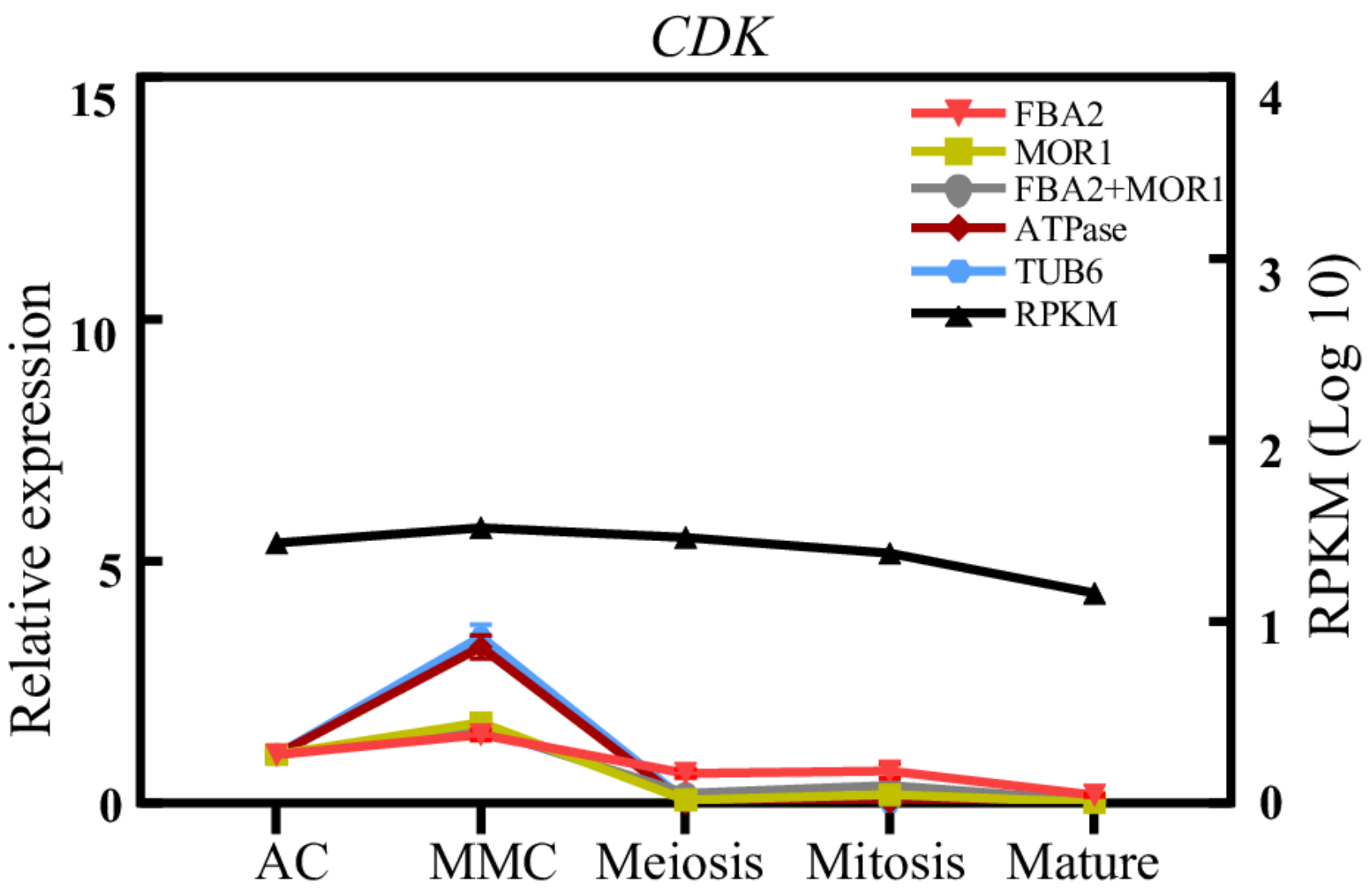

B

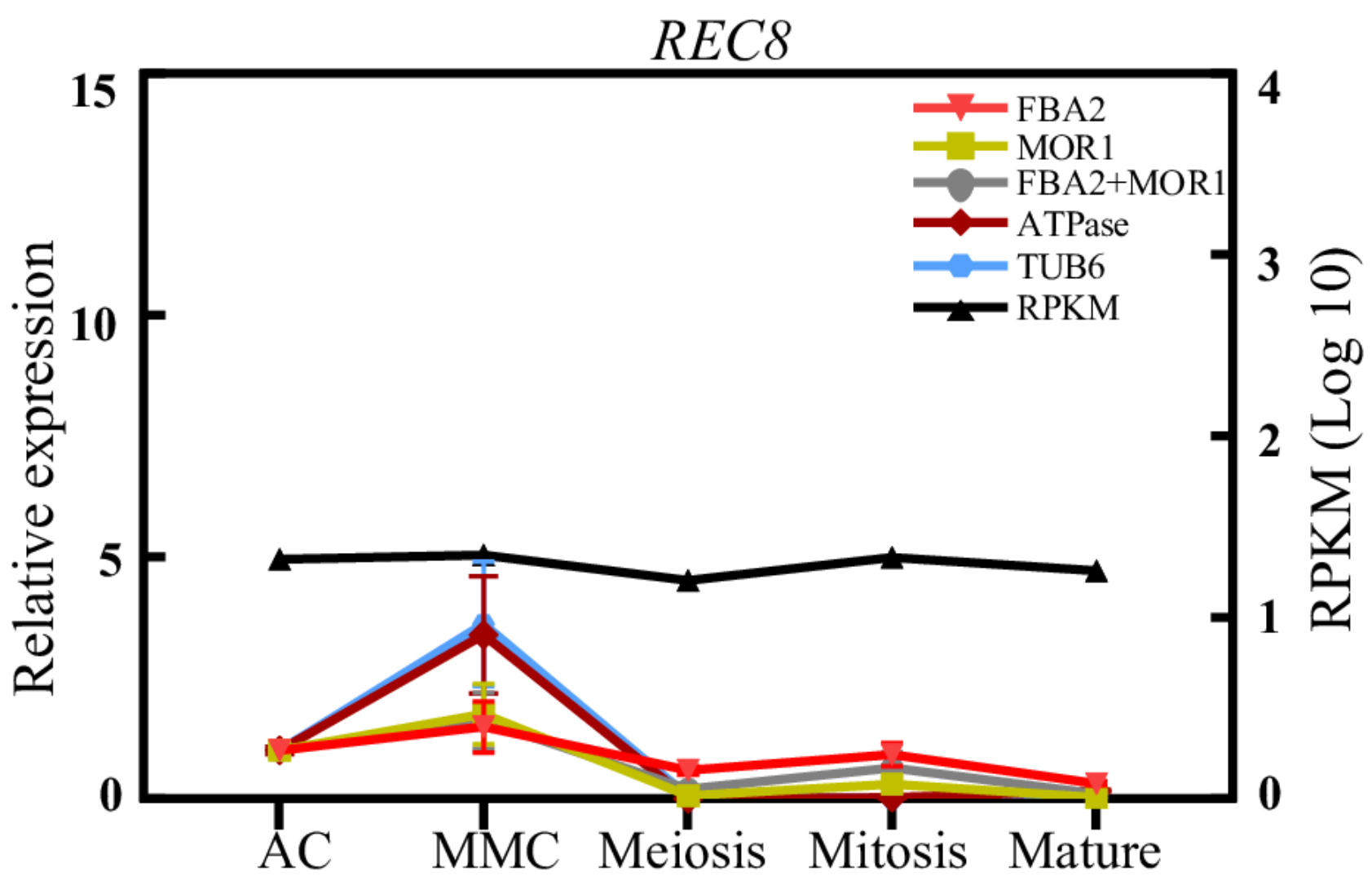




\section{Table 1 (on next page)}

Table 1. The primers and amplification information of candidate reference genes. 
Table 1. The primers and amplification information of candidate reference genes.

\begin{tabular}{|c|c|c|c|c|c|c|c|c|}
\hline $\begin{array}{c}\text { Gene ID / } \\
\text { name }\end{array}$ & $\begin{array}{c}\text { Genbank } \\
\text { No. }\end{array}$ & Mean & SD & $\mathrm{CV}$ & $\begin{array}{c}\text { Primers } \\
(\mathbf{F} / \mathbf{R})\end{array}$ & length & $\begin{array}{c}\mathrm{E} \\
(\%)\end{array}$ & $\mathbf{R 2}$ \\
\hline $\begin{array}{l}\text { Sspon.03G0028120 } \\
\text { / FAB2 }\end{array}$ & MW888380 & 27.71 & 1.72 & 0.06 & $\begin{array}{l}\text { ACCCTTGCTTCAAGGATCAG } \\
\text { GTTGGACTTCCCTGCCATATAC }\end{array}$ & 103 & 1.01 & 0.998 \\
\hline $\begin{array}{l}\text { Sspon.01G0006710 } \\
\text { / LOG2 }\end{array}$ & MW888381 & 23.17 & 4.91 & 0.21 & $\begin{array}{l}\text { GGAACTAGGTATGAACTGCAAGA } \\
\text { CGGCTCTGAGAGGCAAATAA }\end{array}$ & 108 & 0.99 & 0.999 \\
\hline $\begin{array}{l}\text { Sspon.08G0004380 } \\
\text { / VHA }\end{array}$ & MW888382 & 22.25 & 4.52 & 0.20 & $\begin{array}{l}\text { AATTGTCGGTGCTGTCTCTC } \\
\text { AGCCAGCTTCTTATCCAATCC }\end{array}$ & 106 & 1.02 & 0.998 \\
\hline $\begin{array}{l}\text { Sspon.01G0037150 } \\
\text { / MCB1 }\end{array}$ & MW888383 & 21.73 & 4.16 & 0.19 & $\begin{array}{l}\text { CTTGCTCTGCGGTTGTCTAT } \\
\text { GTTTGAGCTTGAGGCATTGTT }\end{array}$ & 111 & 0.99 & 0.995 \\
\hline $\begin{array}{l}\text { Sspon.06G0026890 } \\
\text { / ATPase }\end{array}$ & MW888384 & 21.16 & 4.83 & 0.23 & $\begin{array}{l}\text { CGATGCGCAAGATGAAGAATG } \\
\text { CGTCCAGATCAAACGGTCTATT }\end{array}$ & 111 & 0.97 & 0.996 \\
\hline $\begin{array}{l}\text { Sspon.08G0021360 } \\
\text { / ARM }\end{array}$ & MW888385 & 22.44 & 5.97 & 0.27 & $\begin{array}{l}\text { ACAGGGATCAGATGCACAAG } \\
\text { GAGGGAGTCACACCGAATAAAT }\end{array}$ & 89 & 1.01 & 0.999 \\
\hline $\begin{array}{l}\text { Sspon.01G0020070 } \\
\text { / TIC110 }\end{array}$ & MW888386 & 23.79 & 3.62 & 0.15 & $\begin{array}{l}\text { CAGTACCTGCTGGGCATAAG } \\
\text { AAAGGCCAACTCСТCTTTCTC }\end{array}$ & 105 & 1.00 & 0.999 \\
\hline $\begin{array}{l}\text { Sspon.03G0026510 } \\
\text { /VLN3 }\end{array}$ & MW888387 & 26.09 & 1.89 & 0.07 & $\begin{array}{l}\text { GTCGACAGGGTTGTCATAACT } \\
\text { CCCATCTACTGCAGCATCTT }\end{array}$ & 111 & 1.04 & 0.998 \\
\hline $\begin{array}{l}\text { Sspon.03G0047080 } \\
\text { / GET4 }\end{array}$ & MW888388 & 24.52 & 7.18 & 0.29 & $\begin{array}{l}\text { CGCTTCTATGCTGGTGAACT } \\
\text { GGTTCCCTTGAGATAGGTACATT }\end{array}$ & 98 & 0.99 & 0.995 \\
\hline $\begin{array}{l}\text { Sspon.03G0004010 } \\
\text { / MOR1 }\end{array}$ & MW888389 & 25.75 & 3.11 & 0.12 & $\begin{array}{l}\text { CTAGCTCAGGTGGAGAAGAATG } \\
\text { GCAAACTTTGGAGAGGGTATTG }\end{array}$ & 101 & 0.99 & 0.998 \\
\hline $\begin{array}{l}\text { Sspon.07G0009240 } \\
\text { / EF1 } \alpha\end{array}$ & MW888390 & 24.70 & 6.09 & 0.25 & $\begin{array}{l}\text { CCTCCAGGATGTGTACAAGATT } \\
\text { ACCGAAGGTGACAACCATAC }\end{array}$ & 97 & 0.98 & 0.999 \\
\hline $\begin{array}{l}\text { Sspon.03G0016270 } \\
\text { / TUB6 }\end{array}$ & MW888391 & 21.23 & 4.59 & 0.22 & $\begin{array}{l}\text { TGCATTGGTACACTGGTGAG } \\
\text { GTACTGCTGGTACTCGGAAAC }\end{array}$ & 92 & 1.04 & 0.998 \\
\hline $\begin{array}{l}\text { Sspon.08G0001560 } \\
\text { / GAPDH }\end{array}$ & MW888392 & 19.76 & 5.71 & 0.29 & $\begin{array}{l}\text { CCGTGGATGTGTCAGTTGT } \\
\text { CCCTCAGATGCAGCCTTAATAG }\end{array}$ & 94 & 1.00 & 0.996 \\
\hline $\begin{array}{l}\text { Sspon.08G0008230 } \\
\text { / UBC28 }\end{array}$ & MW888393 & 20.74 & 5.40 & 0.26 & $\begin{array}{l}\text { GGCCCTGTTGCTGAAGATATG } \\
\text { TAGTCCGGTGGGAAGTGAATAG }\end{array}$ & 110 & 1.00 & 0.998 \\
\hline $\begin{array}{l}\text { Sspon.01G0003870 } \\
\text { / PP2A }\end{array}$ & MW888394 & 19.59 & 6.22 & 0.32 & $\begin{array}{l}\text { CAGGACATATCGGAGCAGTTT } \\
\text { GCCCAGTTATATCCCTCCATAAC }\end{array}$ & 89 & 1.01 & 0.996 \\
\hline $\begin{array}{l}\text { Sspon.01G0058300 } \\
\text { / Expressed }\end{array}$ & MW888395 & 23.37 & 7.09 & 0.30 & $\begin{array}{l}\text { CAGTTGTCGAGGGCACTAAA } \\
\text { GCTCAGCATCATTCAGTAAATCC }\end{array}$ & 96 & 1.02 & 0.998 \\
\hline $\begin{array}{l}\text { Sspon.02G0047450 } \\
\text { / ACT7 }\end{array}$ & MW888396 & 19.13 & 10.30 & 0.54 & $\begin{array}{l}\text { GAGCTATGAGTTGCCTGATGT } \\
\text { CCAGGAGCTTCCATCCTAATC }\end{array}$ & 99 & 0.99 & 0.996 \\
\hline $\begin{array}{l}\text { Sspon.01G0006610 } \\
\text { / ACT }\end{array}$ & MW888397 & 19.09 & 9.58 & 0.50 & $\begin{array}{l}\text { CCAGCAGGAGTTCTACATCAG } \\
\text { CCTCTCGATGGCTGCTTG }\end{array}$ & 100 & 1.01 & 0.996 \\
\hline
\end{tabular}

2 
3 Note: The name, ID and sequence information of these genes is from the Saccharum Genome 4 Database.

5

(http://sugarcane.zhangjisenlab.cn/sgd/html/index.html )

6

7

8

9

10

11

12 
Table 2 (on next page)

Gene expression stability ranked by geNorm, NormFinder, BestKeeper and Comprehensive ranking 
Table 2. Gene expression stability ranked by geNorm, NormFinder, BestKeeper and Comprehensive ranking.

\begin{tabular}{|c|c|c|c|c|c|c|c|c|}
\hline \multirow{2}{*}{ Rank } & \multicolumn{2}{|c|}{ geNorm } & \multicolumn{2}{|c|}{ NormFinder } & \multicolumn{2}{|c|}{ BestKeeper } & \multicolumn{2}{|c|}{ Comprehensive Ranking } \\
\hline & Gene & Stability & Gene & Stability & Gene & $\mathrm{CV}(\%) \pm \mathrm{SD}$ & Gene & Geomean value \\
\hline 1 & $M C B 1$ & 0.15 & MORI & 0.09 & $F B A 2$ & $5.48 \pm 1.52$ & $F B A 2$ & 2.00 \\
\hline 2 & $L O G 2$ & 0.15 & $F B A 2$ & 0.10 & $V L N 3$ & $6.28 \pm 1.63$ & MORI & 2.00 \\
\hline 3 & MOR1 & 0.35 & TIC110 & 0.10 & TIV110 & $11.29 \pm 2.68$ & $M C B 1$ & 2.71 \\
\hline 4 & TIC110 & 0.50 & $M C B 1$ & 0.26 & MOR1 & $11.37 \pm 2.92$ & TIC110 & 3.00 \\
\hline 5 & $F B A 2$ & 0.60 & $L O G 2$ & 0.41 & $M C B 1$ & $17.72 \pm 3.85$ & $L O G 2$ & 3.27 \\
\hline 6 & $V L N 3$ & 0.88 & $V L N 3$ & 0.80 & $V H A$ & $18.71 \pm 4.16$ & $V L N 3$ & 3.91 \\
\hline 7 & $V H A$ & 1.11 & $V H A$ & 1.12 & $L O G 2$ & $19.28 \pm 4.46$ & $V H A$ & 6.32 \\
\hline 8 & $E F 1 \alpha$ & 1.39 & $E F 1 \alpha$ & 1.50 & ATPase & $20.32 \pm 4.30$ & $E F 1 \alpha$ & 8.24 \\
\hline 9 & ATPase & 1.61 & ATPase & 1.74 & TUB6 & $20.38 \pm 4.32$ & ATPase & 8.32 \\
\hline 10 & TUB6 & 1.95 & TUB6 & 2.22 & $E F 1 \alpha$ & $21.69 \pm 5.35$ & TUB6 & 9.32 \\
\hline
\end{tabular}

